\title{
The influence of frequency of sucrose intake on serum lipid, protein and carbohydrate levels
}

\author{
BY I. MACDONALD, BETTY L. COLES, JUDITH BRICE \\ AND M. H. JOURDAN \\ Departments of Physiology and Dietetics, Guy's Hospital Medical School, \\ London, $S E \mathrm{I}$
}

(Received 9 July 1969-Accepted 27 October 1969)

\begin{abstract}
I. The changes in serum lipid and protein concentrations, and in carbohydrate tolerance were studied in eleven young male volunteers during a 3 -week period of either nibbling or gorging a diet containing a high proportion of sucrose.

2. It was found that when gorging, the serum glyceride concentration rose early in the dietary period and reached a plateau, that the serum albumin concentration fell and that the glucose tolerance remained unchanged, although there was evidence for an increased rate of absorption of glucose.

3. On the nibbling régime, the serum glyceride concentration rose progressively over the 3-week period, the serum phospholipid concentration fell significantly and the serum albumin concentration fell but to a lesser degree than when gorging.

4. The glucose tolerance was improved when nibbling, and again there was evidence for an increased absorption of glucose.

5. An attempt is made to interrelate these findings.
\end{abstract}

It is known that the frequency with which a given quantity of food is taken can influence metabolism (Cohn, I963). Some undesirable effects, in man, such as obesity and ischaemic heart disease may be associated with taking infrequent meals (gorging) (Fábry, Fodor, Hejl, Braun \& Zvolánková, I964; Fábry, Fodor, Hejl, Geizerová \& Balcarová, 1968). It has also been found that men who take five or more meals per day (nibbling) have a significantly lower serum cholesterol:phospholipid ratio than those who gorge (Hejda \& Fábry, I964).

In some subjects, increasing the dietary carbohydrate produces an increase in fasting serum lipids, especially the glyceride fraction (Ahrens, Hirsch, Oettle, Farquhar \& Stein, I96r), and it is possible that sucrose is more potent in this regard than other dietary carbohydrates (Macdonald \& Braithwaite, 1964; Kuo \& Bassett, 1965; Kaufmann, Poznanski, Blondheim \& Stein, 1966). It was therefore decided to investigate the effects on serum lipids of gorging and nibbling sucrose in a diet which contained a high proportion of this carbohydrate. Previous work has shown that a high carbohydrate intake is associated with a significant fall in serum albumin, though the nature of the carbohydrate is not a factor (Coles \& Macdonald, 1966; Coles, 1969) and it has been found that a high sucrose intake impairs the glucose tolerance after glucose loads (Cohen \& Teitelbaum, 1964). For these reasons the effects of gorging and nibbling sucrose on the serum protein levels were also determined and the carbohydrate tolerance was assessed by giving a sucrose test meal at the beginning and end of each dietary period. 


\section{METHODS}

\section{Subjects}

The subjects were eleven male students aged $20-22$ years weighing $63 \cdot 3-77 \cdot 7 \mathrm{~kg}$ (average $=69.5 \mathrm{~kg}$ ). They were not restricted in any way except that their meals had to be taken in a metabolic laboratory.

\section{Diet}

The average dietary intake of each subject before the experiment started was assessed and the percentage of calories derived from the various food groups is given in Table $I$. The experimental diet, which was taken for $18 \mathrm{~d}$, consisted of lean meat, white fish, green vegetables and unsweetened fruit eaten at midday and $17.30 \mathrm{~h}$. The sucrose intake was $7 \mathrm{~g} / \mathrm{kg}$ body-weight per $\mathrm{d}$ and, when gorging, half the daily amount was taken at $08.00 \mathrm{~h}$ and the remainder at $21.00-22.00 \mathrm{~h}$. During nibbling, the sucrose was taken six times a day, when awakening, mid-morning, after lunch, tea-time, after supper and before retiring. The mean daily dietary intake of each individual on the experimental diet is given in Table 2. Six subjects gorged first and five nibbled first, there being at least a month between the end of one experiment and the beginning of another in each person.

Table I. Calorie intake from protein, fat and carbohydrate, sucrose intake, and body-weight of each individual before the experimental period

\begin{tabular}{|c|c|c|c|c|c|}
\hline \multirow[b]{2}{*}{ Subject } & \multicolumn{3}{|c|}{ Caloric intake ( $\%$ total calories) from: } & \multirow{2}{*}{$\begin{array}{c}\text { Sucrose } \\
\text { intake } \\
(\mathrm{g} / \mathrm{d})\end{array}$} & \multirow{2}{*}{$\begin{array}{c}\text { Initial } \\
\text { weight } \\
\text { (kg) }\end{array}$} \\
\hline & Protein & Fat & Carbohydrate & & \\
\hline J.C & 13 & $4 \mathrm{I}$ & 46 & 130 & $65 \cdot 9$ \\
\hline J.D. & 14 & $4 I$ & 45 & 90 & $64 \cdot 5$ \\
\hline R.L. & I I & 42 & 47 & $\operatorname{II} 5$ & $66 \cdot 8$ \\
\hline J.M. & 12 & 47 & $4 I$ & 70 & $73 \cdot 6$ \\
\hline J.T. & 12 & 45 & 43 & 65 & $66 \cdot 8$ \\
\hline B.W. & II & 42 & 47 & 135 & $76 \cdot 5$ \\
\hline P.B. & I 2 & $4 I$ & 47 & 80 & $72 \cdot 7$ \\
\hline I.L. & I I & 38 & 50 & 175 & $75 \cdot 5$ \\
\hline S.R. & r2 & 32 & $5^{6}$ & 145 & $66 \cdot 4$ \\
\hline D.S. & 12 & 40 & 48 & 205 & $70 \cdot 5$ \\
\hline M.W. & $\mathrm{I} 2$ & 37 & $5 \mathrm{I}$ & 135 & 63.6 \\
\hline
\end{tabular}

\section{Procedures}

The subjects weighed themselves, clothed but without jacket and shoes, at the beginning and end of each experimental period. Samples ( $10 \mathrm{ml}$ ) of blood were taken by venepuncture on the first morning of the experiment (day o) after a $12 \mathrm{~h}$ fast. Subsequent fasting samples were taken on days $3,7,10,1_{4}$ and 18 of the experimental period. On the morning the diet commenced each subject was given I $\mathrm{g}$ sucrose $/ \mathrm{kg}$ body-weight in $2 \mathrm{ml}$ water $/ \mathrm{kg}$ body-weight, and venous and free-running capillary blood samples were obtained as near simultaneously as possible at timed intervals up to $2 \mathrm{~h}$. Glucose concentration was determined in the capillary and venous blood, and serum fructose, lipids and protein were estimated in the venous serum. This procedure was repeated at the end of the experimental period. 


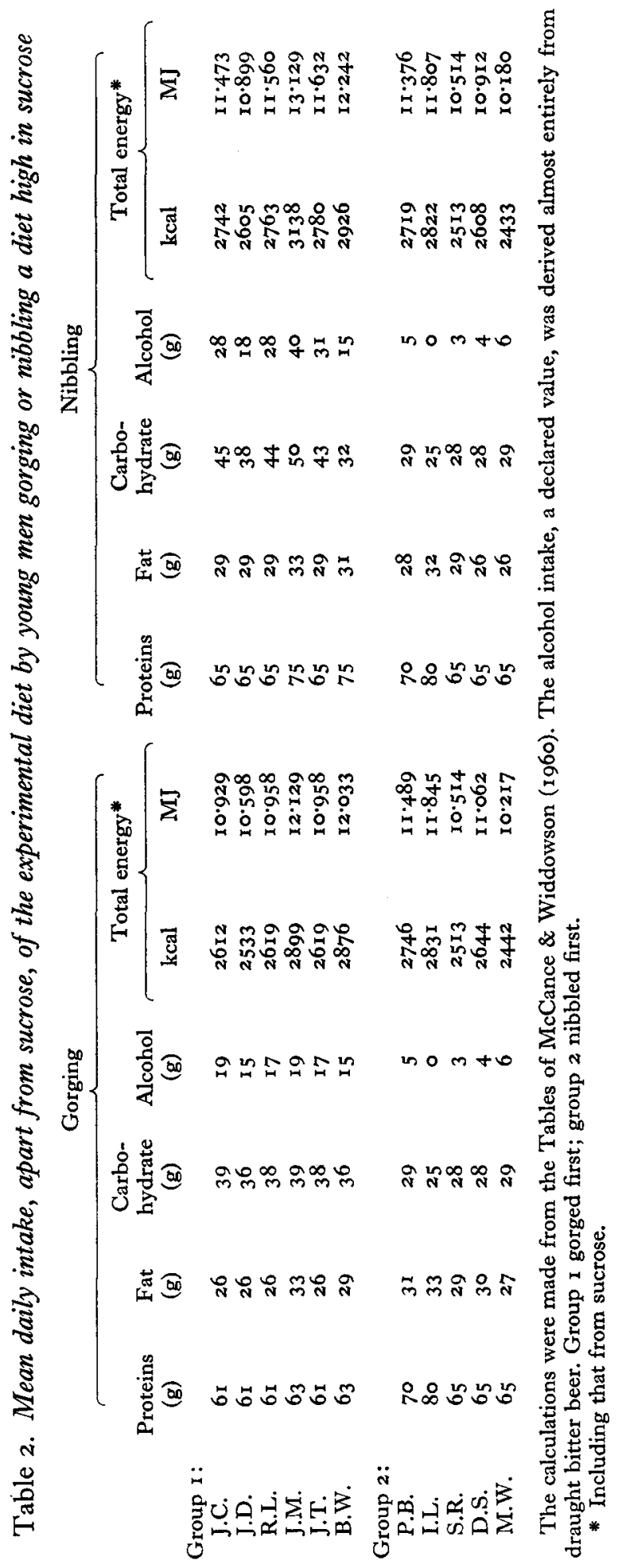




\section{Analytical procedures}

Lipids. The method of extraction and separation of the serum lipids has been described previously (Macdonald, I968). In brief, the lipids were extracted with Bloor's reagent and separated by chromatography on thin-layer silica. The various fractions were then estimated gravimetrically.

Proteins. The serum proteins were estimated on days 0 and 18 of the experiment. The various protein fractions were separated by electrophoresis on cellulose acetate membrane using a barbiturate buffer of $\mathrm{pH} 8.6$ and a current of $0.4 \mathrm{~mA}$ per $\mathrm{cm}$ width of strip. They were then stained in $0.2 \%$ Ponceau $\mathrm{S}$ in $3 \%$ trichloroacetic acid for Io min. After washing in $5 \%$ acetic acid they were blotted dry and cleared with Shell Ondina oil I7. They were then evaluated with a Chromoscan apparatus (Joyce-Loebl and Co. Ltd, Gateshead on Tyne). This apparatus has a built-in integrator which gives a direct value for the area under the curve produced by the scan of each fraction. After adjustment for base-line counts the percentage of each fraction was calculated. The total proteins were estimated by an automated biuret method and the absolute concentration for each fraction was calculated.

Carbohydrates. Blood glucose was determined by an automated method using glucose oxidase (Faulkner, 1965), and serum fructose by an automated modification of the method of Roe (1934).

Table 3. Mean concentrations with their standard errors of the lipid fractions in fasting serum ( $\mathrm{mg} / \mathrm{I} 00 \mathrm{ml}$ ) of eleven young men before the experiment and while gorging or nibbling a diet high in sucrose

\begin{tabular}{|c|c|c|c|c|c|c|c|c|c|c|c|c|}
\hline \multirow[b]{2}{*}{ Lipid fraction } & \multicolumn{2}{|c|}{ 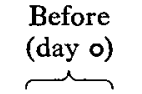 } & \multicolumn{2}{|c|}{$\overbrace{}^{\text {Day } 3}$} & \multicolumn{2}{|c|}{ Day 7} & \multicolumn{2}{|c|}{ Day Io } & \multicolumn{2}{|c|}{ Day I4 } & \multicolumn{2}{|c|}{ Day I8 } \\
\hline & $\bar{x}$ & SE & $\bar{x}$ & SE & $\bar{x}$ & $\mathrm{SE}$ & $\bar{x}$ & $\mathrm{SE}$ & $\bar{x}$ & $\mathrm{SE}$ & $\bar{x}$ & SE \\
\hline \multicolumn{13}{|c|}{ Gorging } \\
\hline Glycerides & 93 & $7 \cdot 3$ & 104 & $8 \cdot I$ & 109 & $11 \cdot 7$ & 108 & $12 \cdot 3$ & 103 & $8 \cdot 3$ & 103 & \\
\hline Cholesterol esters & 225 & 8.0 & 184 & $8 \cdot 1$ & 183 & $8 \cdot I$ & 174 & $8 \cdot 7$ & 187 & $7 \cdot 8$ & I 74 & $7 \cdot 6$ \\
\hline Free cholesterol & 46 & $5 \cdot 4$ & 36 & 377 & 38 & $5 \cdot 1$ & 34 & $2 \cdot 9$ & 39 & $5 \cdot 7$ & 43 & $4 \cdot 2$ \\
\hline Phospholipids & 210 & I $8 \cdot 3$ & 212 & $150^{\circ}$ & 226 & $18 \cdot 3$ & 208 & $16 \cdot 5$ & 210 & $14 \cdot 4$ & $19 \mathrm{I}$ & $13 \cdot 2$ \\
\hline \multicolumn{13}{|c|}{ Nibbling } \\
\hline Glycerides & 87 & $7 \cdot 1$ & 98 & 9.5 & 100 & $8 \cdot I$ & 96 & 4.9 & 98 & $8 \cdot 1$ & 105 & $8 \cdot 7$ \\
\hline Cholesterol esters & 228 & IO. I & 199 & $7 \cdot 7$ & I 84 & II $\cdot 0$ & I76 & $7 \cdot 0$ & 176 & $8 \cdot 6$ & 174 & $9 \cdot 0$ \\
\hline Free cholesterol & 42 & 4.5 & 39 & $3 \cdot 5$ & 37 & $4^{\prime} I$ & 34 & 3.2 & 35 & $3 \% 4$ & 33 & $3 \cdot 1$ \\
\hline Phospholipids & 239 & 19.4 & 207 & $18 \cdot 1$ & 201 & $17 \cdot 2$ & 195 & I 57 & 194 & 19.3 & 203 & $20 \cdot I$ \\
\hline
\end{tabular}

\section{RESULTS}

\section{Body-weight}

There was a mean loss of weight of $0.6 \mathrm{~kg}$ (SE $\pm 0 \cdot 10)$ during the gorging period and a mean loss of $0.4 \mathrm{~kg}$ ( $\mathrm{SE} \pm 0 . \mathrm{IO}$ ) during nibbling. These weight losses were statistically significant but the difference between them was not significant. 


\section{Lipids}

For each of the lipid fractions estimated, the mean values, with their standard errors, are seen in Table 3 . In view of the variation between individuals in the levels of the various fractions, it was decided to calculate the values as a percentage rise or fall from the value found at the commencement of each experimental period.

Triglycerides. There was a significant percentage increase at days 3 and 7 during gorging, and at days 14 and 18 during nibbling. The slope of a regression line, fitted by the method of least squares, was significant during nibbling (Fig. I).

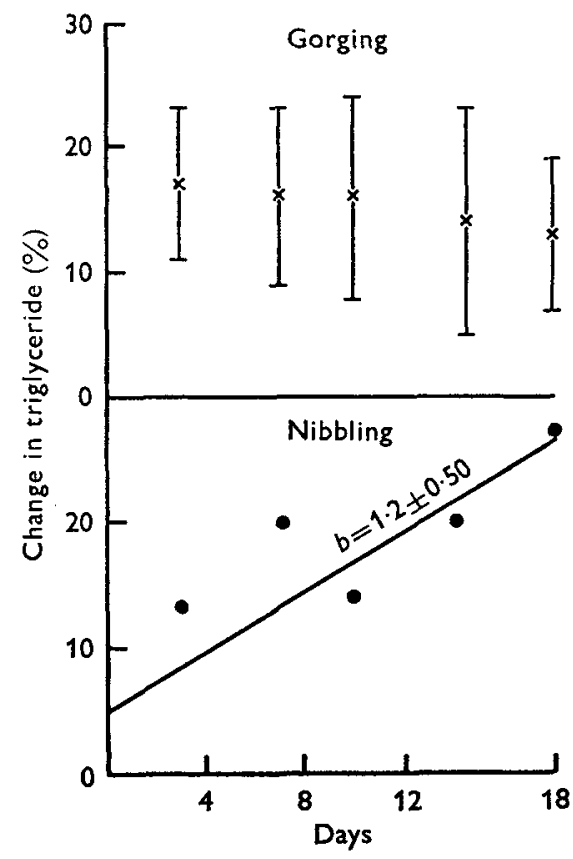

Fig. I. Mean of the percentage change in fasting serum triglyceride concentration, in young men gorging or nibbling a diet high in sucrose, plotted against the days on the diet. For the gorging régime, the means and standard errors are shown; for the nibbling régime a regression line has been calculated using all the results between 0 and $18 \mathrm{~d}$.

Cholesterol. There was a significant percentage decrease in the total cholesterol calculated during each dietary experiment and no difference between nibbling and gorging was found. This fall was presumably due to the low cholesterol content of the diet (Connor, r96r).

Phospholipids. A significant fall was found in this lipid fraction at all times during the nibbling period, but at no time during the gorging. The slope of the regression line during nibbling was significant.

\section{Proteins}

One subject had had a throat infection just before day o of the nibbling régime. His serum proteins showed a grossly abnormal pattern on this occasion and have been omitted from the results. The mean differences between the concentration of the 
various serum protein fractions at the beginning and end of the diets, together with the standard error of the difference, are shown in Table 4. When the change in serum albumin concentration was assessed for each individual there was a significant decrease for the group as a whole with both dietary régimes.

The difference in the concentration of the various serum protein fractions between the Ist and last day of the diet were determined for each subject. These values for all subjects and for each fraction were summed and the mean and standard error calculated (Table 4). There was a significant decrease in the serum albumin concentration on both dietary régimes. The fall in albumin concentration was significantly greater after gorging than after nibbling $(0.005>P>0.001)$. No significant changes in the concentrations of any of the other protein fractions were noted on either of the régimes.

Table 4. Mean differences with their standard errors $(\mathrm{g} / \mathrm{1} 00 \mathrm{ml})$ in the concentration of the various fractions in the serum of young men between days $\mathrm{I} 8$ and $\mathrm{O}$ of gorging or nibbling a diet high in sucrose

$\begin{array}{lcccc}\text { Fraction } & \text { Mean difference } & \text { SE } & \text { Mean difference } & \text { SE } \\ \text { Albumin } & -0.74 & 0.10 & -0.24 & 0.08 \\ \alpha_{1} \text {-Globulin } & -0.01 & 0.02 & +0.05 & 0.02 \\ \alpha_{2} \text {-Globulin } & +0.01 & 0.05 & +0.02 & 0.04 \\ \beta \text {-Globulin } & +0.06 & 0.05 & -0.01 & 0.04 \\ \gamma \text {-Globulin } & +0.10 & 0.10 & -0.08 & 0.06\end{array}$

Figures in parentheses are the numbers of subjects.

\section{Carbohydrates}

Glucose. The mean capillary blood glucose values after a sucrose load, both before and after gorging, are shown in Table 5. There was no change in the fasting values for capillary blood glucose at the end of the gorging period, but there was a greater rise in glucose concentration in the capillary blood after a sucrose load after the subjects had gorged. Within-subject analysis by Student's $t$ test showed this to be significant $(P<0.005)$. However, the rate at which the capillary glucose concentration subsequently fell during the sucrose tolerance test did not change after gorging.

Table 5 also shows that there was no change in the mean capillary-venous difference in glucose concentration after gorging.

The glucose values before and after nibbling are shown in Table 5. The fasting value for glucose concentration in the capillary blood was significantly lower following nibbling $(P<0.05)$ and there was a greater rise in capillary glucose concentration, followed by a greater rate of fall in response to the sucrose load after $18 \mathrm{~d}$ of nibbling as compared with before nibbling $(P<0.05)$. No significant change in the capillaryvenous difference was found for blood glucose concentration. Fig. 2 shows the mean fasting values for serum glucose during the gorging and nibbling periods. There was a significant rise up to day 15 while gorging $(P<0.00 r)$ but not while nibbling.

Fructose. Table 5 shows the mean serum fructose levels achieved during the sucrose 


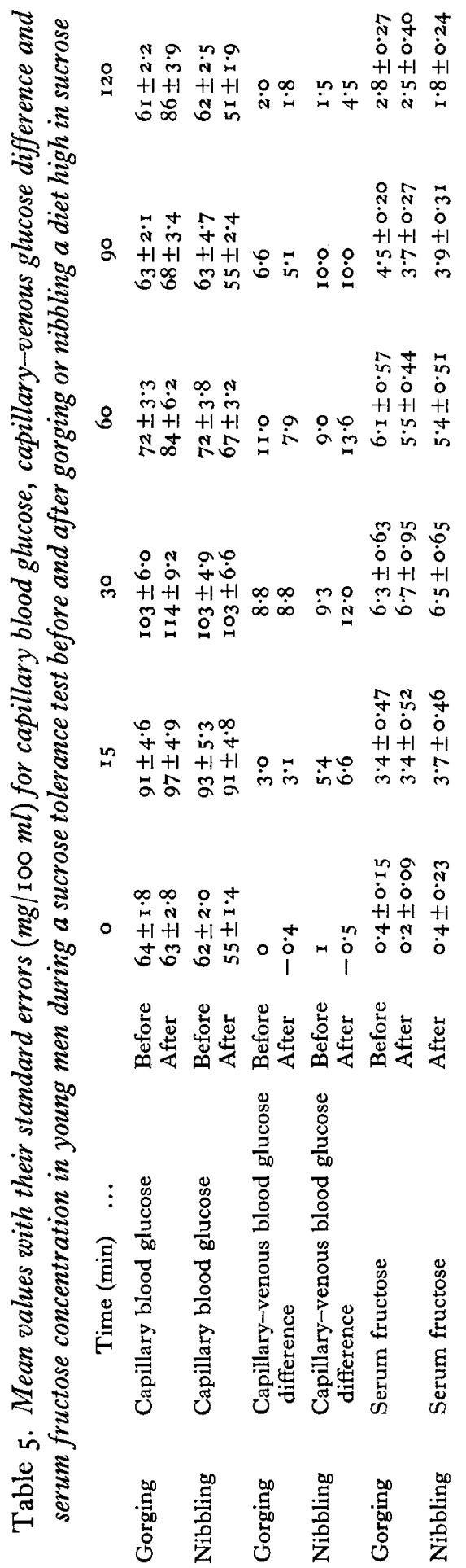


tolerance test before and after gorging and after nibbling. Unfortunately results before nibbling were incomplete and these have been omitted. However, within-subject analysis shows there to be no significant difference between the values achieved before and after gorging, or after gorging and after nibbling.

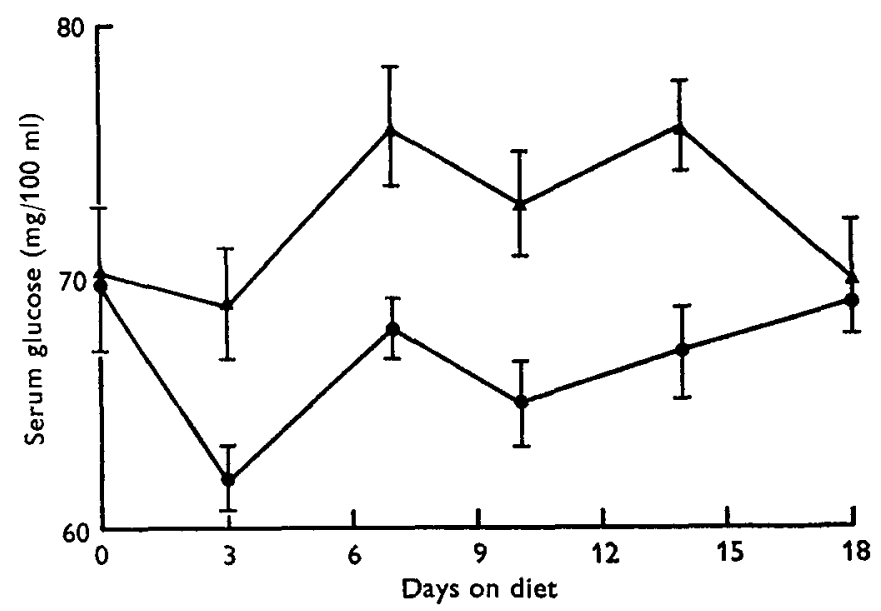

Fig. 2. Mean fasting serum glucose concentrations, with their standard errors, in young men gorging or nibbling a diet high in sucrose, plotted against the days on the diet. $\boldsymbol{\Delta}-\boldsymbol{\Lambda}$, gorging; - 1 , nibbling.

\section{DISCUSSION}

The metabolism of fat, protein and carbohydrates in animals is apparently affected by the frequency of food intake (Cohn \& Joseph, r960; Cohn \& Allweiss, r963; Leveille \& Chakrabarty, ig68). In man the evidence for such a relationship is less conclusive. Gwinup, Byron, Roush, Kruger \& Hamwi (1963) showed that when the frequency of eating was increased from three to ten times a day, there was a decrease in fasting serum cholesterol, phospholipids and esterified fatty acids. On the other hand Beveridge, Jagannathan \& Connell (1964), using formula diets, were not able to demonstrate differences in serum cholesterol or triglyceride levels when the daily intake was spread over eight meals or when two-thirds was taken in one meal. Hodges $\&$ Krehl (1965) found a reduction in serum cholesterol and glyceride levels when subjects changed from meals of irregular size to meals of equal size. Irwin \& Feeley (1967) found in fifteen young women that the serum cholesterol level was lower when the diet was fed in three equal meals a day than when fed in two small and one large meal per day. However, when the diet was served in six equal meals per day the cholesterol level was intermediate between that observed on the regimen with three meals per day and on that with two small and one large meal per day. Irwin \& Feeley found no significant change in the levels of phospholipids, glycerides and total fatty acids.

The diet in this experiment was abnormal in that the amount of sucrose is large compared to that normally taken by the subjects. This excessive intake of sucrose was chosen in order to amplify any response to the sucrose, and the responses that were 
observed may or may not take place when the sucrose intake is less. Nevertheless, the frequency of sucrose intake in these circumstances did alter the lipid response. The gradual rise in the concentration of fasting serum triglycerides while nibbling, not seen during gorging, suggests that the more frequently applied stimulus of sucrose resulted in gradual changes whose plateau had not been reached by $18 \mathrm{~d}$. During gorging the triglyceride concentration rose early in the experiment and then rose no further, suggesting the rapid development of a new balance.

The significant and marked fall in serum phospholipids associated with nibbling is in line with results reported by Gwinup et al. (1963). These workers found, in addition, an increase in serum phospholipid concentration during gorging, whereas in the findings reported here no significant change was found.

Most investigations into the metabolic effects of the frequency of eating have centred on obesity and blood lipids, and less attention has been paid to the effect on protein metabolism. Wu \& Wu (1950) studied the effect of meal frequency on the nitrogen metabolism of a healthy male subject. They found that with a protein intake of $\mathrm{I} \cdot \mathrm{I} 4 \mathrm{~g} / \mathrm{kg}$ daily the subject was in positive nitrogen balance when taking four meals daily but in negative balance when eating the same amount of food in two meals. When the protein intake was reduced to $0.73 \mathrm{~g} / \mathrm{kg}$, meal frequency no longer affected the nitrogen balance. The mean daily protein intake in the present experiment was $0.95 \mathrm{~g} / \mathrm{kg}$, so that some effect might be expected. Cohn \& Joseph (rg68) found that the carcasses of meal-fed (gorging) rats contained significantly more fat and less protein than rats allowed free access to food. They concluded that gorging rats catabolized protein and synthesized and stored fat. Irwin \& Feeley (1967), however, could not demonstrate any difference in nitrogen retention in a group of healthy women fed either three or six meals daily. Braun, Vrána \& Fábry (I967) and Chakrabarty \& Leveille (r968) suggested that in meal-fed rats the sensitivity to insulin is increased. We have previously discussed the role of insulin in the production of the fall in serum albumin seen on high-carbohydrate diets (Coles \& Macdonald, I966; Coles, I969). The subjects in the present experiment were eating a high-sucrose diet, which has been shown to be associated with a decrease in serum albumin concentration. In the previous experiments subjects took their additional carbohydrate in divided doses as they wished, on fruit or in beverages throughout the day, and this pattern of intake was thus closely allied to that of the nibbling régime. Increased reaction to insulin in gorging subjects, together with a possible effect of food frequency on nitrogen metabolism, could account for the greater decrease in albumin concentration seen with this feeding régime.

Changes in the serum glucose concentration following an oral load of sucrose depend upon a number of factors, including the rate of gastric emptying, the rate of sucrose hydrolysis, the rate of absorption and the serum insulin-like activity induced by the sucrose load.

Measurement of serum insulin by either immuno-assay or biological assay is of limited value, in as much as no indication is obtained as to the sensitivity of the subject's tissues to insulin. Ideally, an in vivo estimate of insulin-like activity is desirable, and in an effort to achieve this the capillary-venous differences in blood 
glucose across muscle tissue have been estimated (Butterfield \& Holling, 1959). No measurements were made of the changes in blood flow through the forearm muscle during the sucrose tolerance test, since it was considered that in a comparison of before and after gorging or nibbling this factor would be constant. The concentration of glucose in free-running blood from an ear capillary was used as an index of the arterial blood glucose concentration (Somogyi, r948).

In the present experiments, gorging sucrose was associated with a greater increase in blood glucose concentration following a sucrose meal, with no change in the subsequent rate of fall of glucose concentration. This suggests an increased rate of absorption of the glucose fraction from sucrose hydrolysis with no change in insulin activity after gorging.

Nibbling sucrose resulted in a significant decrease in the fasting value for glucose concentration in capillary blood. Although the initial rise in this concentration following the sucrose meal was greater after nibbling than before, again suggesting an increased rate of absorption, the rate at which the capillary blood glucose concentration subsequently fell was much greater after nibbling. Since this is associated with a slight increase in the apparent glucose uptake by muscle tissue, it would seem that after nibbling there is a greater insulin-like activity induced by a given degree of hyperglycaemia. This may indicate an improved glucose tolerance.

The results of the present experiments agree with those of Gwinup et al. (1963), who studied oral glucose tolerance in four individuals fed a diet containing $38 \%$ carbohydrate either as a single meal or two separate meals. In those experiments no measurements of insulin or insulin-like activity were made, but they found a 'decreased glucose tolerance' following gorging and an 'increased glucose tolerance' following nibbling. Similarly, Cohn \& Allweiss (1963) found 'improved' intravenous glucose tolerance and reduced fasting values for blood glucose in subjects taking six meals/d as compared with values when taking three meals/d.

It is difficult to interrelate the findings of the present experiments, since there is not a sufficient body of factual evidence to allow more than hypothesis.

The fall in serum cholesterol found during both nibbling and gorging was presumably due to the low cholesterol content of the diet, and agrees with findings of Beveridge et al. (x964).

The rise in serum glyceride values and the fall in serum albumin concentration have previously been seen with diets containing a high percentage of sucrose. The fall in serum albumin may be due to a decreased synthesis of albumin by the liver as part of the protein-sparing action of carbohydrates. The rise in serum glycerides could be due to increased synthesis of glycerides by the liver (Reaven, Hill, Gross \& Farquhar, I965) or to decreased rate of removal from the serum.

However, certain differences have been found between the metabolic effects of nibbling and gorging. Thus, there is an increased insulin-like activity produced by a given rise in blood glucose after nibbling as compared with after gorging, and this may be responsible for the lower fasting value found for glucose concentration in capillary blood after nibbling.

Insulin has been shown to increase the uptake of blood amino acids by muscle, and 
to reduce the content of protein in the liver (Munro, Black \& Thomson, 1959). This results in a fall of blood amino acid concentration, a fall in the synthesis of urea by the liver, and possibly a fall in serum albumin production. The greater fall in serum albumin found when gorging may be due to the fact that the serum insulin rises to higher levels during the two meals of sucrose per day while gorging than it does during any of the six meals of sucrose per day while nibbling.

Similarly it is possible that the different pattern in rise of serum glycerides while nibbling as compared with gorging is due to this different pattern of insulin release, but in the absence of more substantial evidence it is not possible to be more definite.

We are very grateful to the volunteers for their co-operation, to the Medical Research Council and to Cadbury Bros Ltd for research grants.

Requests for reprints should be addressed to M. H. Jourdan, Department of Physiology, Guy's Hospital Medical School, London, SE r.

\section{REFERENCES}

Ahrens, E. H., Hirsch, J. Oettle, K., Farquhar, J. W. \& Stein, Y. (r96r). Trans. Ass. Am. Physns 74, 134. Beveridge, J. M. R., Jagannathan, S. N. \& Connell, W. F. (1964). Can. F. Biochem. 42, 999.

Braun, T., Vrána, A. \& Fábry. P. (1 967). Experimentia 23, 468.

Butterfield, W. J. H. \& Holling, H. E. (1959). Clin. Sci. 18, 147.

Chakrabarty, K. \& Leveille, G. A. (1968). F. Nutr. 96, 76.

Cohen, A. M. \& Teitelbaum, A. (I964). Am. F. Physiol. 206, 105.

Cohn, C. (1963). Ann. N.Y. Acad. Sci. 110, 395.

Cohn, C. \& Allweiss, M. D. (I963). Am. F. clin. Nutr. 12, 255.

Cohn, C. \& Joseph, D. (1960). Metabolism 9, 492.

Cohn, C. \& Joseph, D. (I968). F. Nutr. 96, 94.

Coles, B. L. (1969). Br. F. Nutr. 23, $40 \mathrm{I}$.

Coles, B. L. \& Macdonald, I. (1966). Clin. Sci. 30, 37.

Connor, W. E. (I961). Geriatrics 16, 407.

Fábry, P., Fodor, J., Hejl, Z., Braun, T. \& Zvolánková, K. (I964). Lancet ii, 6I 4.

Fábry, P., Fodor, J., Hejl, Z., Geizerová, H. \& Balcarová, O. (1968). Lancet ii, Igo.

Faulkner, D. E. (1965). Analyst, Lond. 90, 736.

Gwinup, G., Byron, R. C., Roush, W., Kruger, F. \& Hamwi, G. J. (1963). Lancet ii, I65.

Hejda, S. \& Fábry, P. (1964). Nutritio Dieta 6, 2 16.

Hodges, R. E. \& KrehI, W. A. (1965). Am. F. clin. Nutr. 17, 334.

Irwin, M. I. \& Feeley, R. M. (1967). Am. F. clin. Nutr. 20, 8 I6.

Kaufmann, N. A., Poznanski, R, Blondheim, S. H. \& Stein, Y. (r966). Am. F. clin. Nutr. r8, 26 I.

Kuo, P. T. \& Bassett, D. R. (1965). Ann. intern. Med. 62, 199.

Leveille, G. A. \& Chakrabarty, K. (1968). F. Nutr. 96, 69.

McCance, R. A. Widdowson, E. M. (1960). Spec. Rep. Ser. med. Res. Coun. no. 297.

Macdonald, I. ( I 968). Am. F. clin. Nutr. 21, I366.

Macdonald, I. \& Braithwaite, D. M. (1964). Clin. Sci. 27, 23.

Munro, H. N., Black, J. G. \& Thomson, W. S. T. (1959). Br. F. Nutr. 13, 475.

Reaven, G. M., Hill, D. B., Gross, R. C. \& Farquhar, J. W. (I965). F. clin. Invest. 44, 1826.

Roe, J. H. (1934). F. biol. Chem. 107, 15.

Somogyi, M. (1948). F. biol. Chem. 174, r89.

Wu, H. \& Wu, D. Y. (1950). Proc. Soc. exp. Biol. Med. 74, 78. 